\title{
Lenalidomide induces apoptosis and inhibits angiogenesis via caspase-3 and VEGF in hepatocellular carcinoma cells
}

\author{
ZHEN QU ${ }^{1,2^{*}}$, CHUNPING JIANG ${ }^{1,2^{*}}$, JUNHUA WU $^{3}$ and YITAO DING ${ }^{1,2}$ \\ ${ }^{1}$ Department of Hepatobiliary Surgery, Drum Tower Hospital, Medicine School of Nanjing University; \\ ${ }^{2}$ Department of Hepatobiliary Surgery, Jiangsu Province's Key Medical Center for Hepatobiliary Surgery, \\ Nanjing, Jiangsu 210000; ${ }^{3}$ Jiangsu Key Laboratory of Molecular Medicine, \\ Medicine School of Nanjing University, Nanjing, Jiangsu 210093, P.R. China
}

Received September 15, 2015; Accepted September 23, 2016

DOI: $10.3892 / \mathrm{mmr} .2016 .5797$

\begin{abstract}
Hepatocellular carcinoma (HCC) remains a disease with a high mortality rate, and the treatment for HCC remains limited. It is necessary to develop efficient and low toxicity drugs for the clinical treatment of HCC. Lenalidomide is a novel analogue of thalidomide and has anti-inflammatory, immunomodulatory and anti-angiogenic effects. The current study investigated the inhibitory effect against HCC cells of lenalidomide and thalidomide. The MTT assay was used to determine the cytotoxicity of lenalidomide and thalidomide, and morphological changes were observed by fluorescence microscopy. Caspase and VEGF protein expression were measured by ELISA analysis and western blotting. It was identified that treatment of cells with lenalidomide and thalidomide led to a dose-dependent inhibition of cell proliferation, and the two drugs were able to induce cells apoptosis and inhibit VEGF expression in HCC cells. In addition, lenalidomide was identified to exhibit greater effects than thalidomide at the same concentration. In conclusion, the results indicated that lenalidomide induces apoptosis and inhibits angiogenesis in HCC cells via caspase- 3 and VEGF pathway, and these may provide a potential perspective for lenalidomide's application in clinical.
\end{abstract}

\section{Introduction}

There is a high incidence of hepatocellular carcinoma (HCC) in China, HCC accounts for more than $80 \%$ of cases of primary liver cancer $(1,2)$. The majority of patients with either HCC or

Correspondence to: Professor Yitao Ding, Department of Hepatobiliary Surgery, Drum Tower Hospital, Medicine School of Nanjing University, 321 Zhongshan Road, Nanjing, Jiangsu 210000, P.R. China

E-mail: drdingyitao0@sina.com

*Contributed equally

Key words: lenalidomide, apoptosis, angiogenesis, VEGF, HCC hepatic metastasis carcinoma are not eligible candidates for surgical resection (3). Transarterial chemoembolization and the orally available targeted drug sorafenib have been demonstrated to increase survival in selected candidates (4). It is necessary to investigate and develop efficient and low toxicity drugs for the clinical treatment of HCC.

The use of thalidomide was terminated due to its teratogenicity (5). Lenalidomide is a new analogue of thalidomide and has been demonstrated to be more potent than thalidomide in the stimulation of T-cells, interleukin (IL)-2, and interferon (IFN) $-\gamma$ production $(6,7)$. Unlike thalidomide, lenalidomide exhibits almost no sedative or constipation-causing properties, and induces only minimal neurotoxicity in the initial clinical application (8). Previous studies have demonstrated that the anti-inflammatory, immunomodulatory and anti-angiogenic of lenalidomide served important roles in its anticancer activity $(9,10)$. Lenalidomide induces apoptosis of myeloma cells and exhibits an immunomodulatory effect on cytokine secretion, enhancing T cell proliferation and IL-2 and IFN- $\gamma$ production in patients with multiple myeloma (MM), and it additionally increases lysis of autologous MM cells through cytotoxicity mediated by natural killer cells $(11,12)$. However, it remains unclear whether it may be efficacious in solid tumors.

In the current study, SMMC-7721 hepatoma cells were treated with lenalidomide or thalidomide at different concentrations, and it was identified that lenalidomide significantly inhibits proliferation of SMMC-7721 hepatoma cells in vitro. The two drugs tested can promote cell apoptosis and inhibit the expression of vascular endothelial growth factor (VEGF). In addition, lenalidomide was identified to be more potent than thalidomide, with observations of cell morphology by microscopy confirming these results. It was suggested that lenalidomide may induce apoptosis through the pathway of caspase- 3 activation.

\section{Materials and methods}

Cells and reagents. The human HCC cell line SMMC-7721 was purchased from the Soochow University Cell Banks (Suzhou, China). Lenalidomide (Natco Pharma Limited, Hyderabad, India) and thalidomide (Sigma-Aldrich; Merck 
Millipore, Darmstadt, Germany) was dissolved in dimethyl sulfoxide (DMSO; Sigma-Aldrich; Merck Millipore) to prepare 10 and $40 \mathrm{mM}$ stock solutions. Cells were stained with Annexin V-Fluorescein Isothiocyanate (FITC) following the manufacturer's instructions (Annexin V-FITC Apoptosis kit; Beijing BLKW Biotechnology Co., Ltd., Beijing, China) and analyzed for apoptosis by FACS using CellQuest software version 7.0 (BD Bioscience, Franklin Lakes, NJ, USA). Flag-tagged caspase-3 was purchased Bio-Box Biotech (Beijing, China). VEGF enzyme-linked immunosorbent assay (ELISA) analysis was performed with a commercial VEGF ELISA kit (cat. no. EH010-56; BLKW Biotechnology, Co., Ltd.) following the manufacturer's protocol. The antibodies for caspase-3 (cat. no. 9664P) and VEGF (cat. no. 2478S) were obtained from Cell Signaling Technology, Inc. (Danvers, MA, USA). GAPDH antibody (cat. no. AB22131) was obtained from Bioworld Technology, Inc. (St. Louis Park, MN, USA) The Cell Counting Kit 8 (CCK-8) was purchased from Dojindo Molecular Technologies, Inc. (Kumamoto, Japan).

Cell culture. SMMC-7721 cells were cultured in Dulbecco's modified Eagle's medium (Gibco; Thermo Fisher Scientific, Inc., Waltham, MA, USA) supplemented with $10 \%$ fetal bovine serum (10\%; Gibco; Thermo Fisher Scientific, Inc.). The SMMC-7721 human HCC cell line was maintained at $37^{\circ} \mathrm{C}$ in a humidified atmosphere with $5 \% \mathrm{CO}_{2}$.

Cell proliferation assay. CCK-8 assay was used to evaluate the relative cell viability. Briefly, cells were plated in 96-well plates at a density of 5,000 cells/well in the media. The cells were pretreated with compounds at $6.25,12.5,25,50$, 100 and $200 \mu \mathrm{g} / \mathrm{ml}$ in a final concentration of $0.25 \%$ DMSO in triplicate at $37^{\circ} \mathrm{C}$ in a humidfied incubator at $5 \% \mathrm{CO}_{2}$ for $48 \mathrm{~h}$. Subsequently, CCK-8 reagent ( $100 \mu \mathrm{l} / \mathrm{ml}$ medium) was applied and incubated with cells at $37^{\circ} \mathrm{C}, 5 \% \mathrm{CO}_{2}$ for $1 \mathrm{~h}$. Cells were then incubated for an additional $4 \mathrm{~h}$ and the optical density (OD) was measured at $450 \mathrm{~nm}$ using a VersaMax Microtiter Plate Reader (Molecular Devices, LLC, Sunnyvale, CA, USA). Relative cell viability was calculated with the following formula: Relative cell viability $(\%)=\mathrm{OD}$ (treatment group)/OD(control group) x $100 \%$. The experiment was performed in triplicate.

Apoptosis assay. Cells $\left(5 \times 10^{5}\right)$ were treated with $100 \mu \mathrm{g} / \mathrm{ml}$ or $200 \mu \mathrm{g} / \mathrm{ml}$ drugs (lenalidomide and thalidomide) for $48 \mathrm{~h}$ then washed once with Annexin-V wash buffer (BD Biosciences). Cells were incubated with Annexin-V binding protein (5 $\mu \mathrm{l})$ and propidium iodide (PI; $10 \mu \mathrm{l}$ ) (BD Biosciences) for $10 \mathrm{~min}$. Cells were diluted with $500 \mu \mathrm{l}$ wash buffer and analyzed by a FACSCalibur flow cytometer using CellQuest software. Furthermore, cells $\left(5 \times 10^{5}\right)$ were treated with the indicated treatments for $48 \mathrm{~h}$, the supernatant was removed, $1 \mathrm{ml} 70 \%$ cold ethanol was added along the six hole plate edge, then cells were fixed for $15 \mathrm{~min}$. The cells were then washed with cold phosphate-buffered saline and PI $(0.5 \mathrm{ml})$ was added prior to observation under the microscope.

Caspase- 3 assay. Cells $\left(5 \times 10^{5}\right)$ were treated with $100 \mu \mathrm{g} / \mathrm{ml}$ or $200 \mu \mathrm{g} / \mathrm{ml}$ of the drugs (lenalidomide and thalidomide) for
$48 \mathrm{~h}$. Lysates $\left(50 \mu \mathrm{l} / 2 \times 10^{6}\right.$ cells $)$ were added, then the cells were reprecipitated, placed in an ice bath for $30 \mathrm{~min}$, during which they were oscillated 3-4 times (10 sec each time), then the crude cytosol was obtained as the supernatant as a result of centrifugation at $6,140 \times \mathrm{g}$ for $20 \mathrm{~min}$ at $4^{\circ} \mathrm{C}$. Cell lysates $(50 \mu 1)$ were then extracted and mixed with Ac-DEVD-pNA (Sigma-Aldrich; Merck Millipore), incubated for $4 \mathrm{~h}$ at $37^{\circ} \mathrm{C}$, and then the OD was measured using a microplate reader. Caspase- 3 activation was determined by the rate of OD induced and OD control. All experiments were performed in triplicates.

ELISA assay. Cells $\left(5 \times 10^{5}\right)$ were treated with lenalidomide and thalidomide at the indicated doses for $48 \mathrm{~h}$. ELISA analysis was performed as previously described (13). VEGF ELISA was performed using $200 \mu \mathrm{l}$ culture supernatant in duplicates using the Quantikine VEGF ELISA kit (BLKW Biotechnology, Co., Ltd.) according to the manufacturer's instructions. Briefly, $200 \mu \mathrm{l}$ culture supernatants was added to the wells and they were incubated for $2 \mathrm{~h}$ at $37^{\circ} \mathrm{C}$. The plate was washed with $400 \mu \mathrm{l}$ wash buffer twice and $200 \mu \mathrm{l}$ VEGF conjugate was added followed by incubation for $2 \mathrm{~h}$. Subsequent to the addition of substrate and stop solution, the optical density was determined using a microplate reader (RT-21000; Rayto Life and Analytical Sciences Co., Ltd., Shenzhen, China) at $450 \mathrm{~nm}$ with wavelength correction of $570 \mathrm{~nm}$.

Western blotting. To determine the level of VEGF proteins, lenalidomide and thalidomide-treated cell lysates were prepared as described. A total of $20 \mu \mathrm{g}$ proteins was analyzed by western blot analysis. The PVDF membranes with the transferred proteins were incubated with primary antibodies (cleaved caspase-3, 1:500; VEGF, 1:1,000; GAPDH, 1:10,000) at $4{ }^{\circ} \mathrm{C}$ overnight and horseradish peroxidase-conjugated secondary antibodies $(1: 10,000$; cat. no. 7074P2; Cell Signaling Technology, Inc.) at room temperature for $2 \mathrm{~h}$. The signal was developed by the enhanced chemiluminescence reagent (EMD Millipore, Billerica, MA, USA) and visualized by FluorChem FC2 Imaging System (Alpha Innotech, San Leandro, CA, USA).

Statistical analysis. Data are expressed as the mean \pm standard deviation. Data analysis was performed using the SPSS software, version 18.0 (SPSS, Inc., Chicago, IL, USA). Difference between groups were assessed with Student's t-test. $\mathrm{P}<0.05$ was considered to indicate a statistically significant difference.

\section{Results}

Lenalidomide inhibits SMMC-7721 cell proliferation. The anti-proliferative rate was detected by CCK-8, results are expressed as the mean \pm standard deviation. Treatment of cells with lenalidomide and thalidomide in different concentrations for $48 \mathrm{~h}$ led to a dose-dependent induction of the inhibition of cell proliferation. The anti-proliferative effects of lenalidomide were identified to be more potent than that of thalidomide in the $25,50,100$ and $200 \mu \mathrm{g} / \mathrm{ml}$ groups $(\mathrm{P}<0.01$; Fig. 1A and Table I). 
Table I. Cell growth inhibition rates in each drug concentration group.

\begin{tabular}{lcc}
\hline \multirow{2}{*}{$\begin{array}{l}\text { Drug concentration } \\
(\mu \mathrm{g} / \mathrm{ml})\end{array}$} & \multicolumn{2}{c}{ Inhibition rate $(\%)$} \\
\cline { 2 - 3 } & Thalidomide & Lenalidomide \\
\hline 6.25 & $1.57 \pm 0.291$ & $4.55 \pm 0.852$ \\
12.5 & $3.01 \pm 0.447$ & $11.05 \pm 0.859$ \\
25 & $7.89 \pm 0.349$ & $17.35 \pm 2.366^{\mathrm{a}}$ \\
50 & $17.28 \pm 1.223$ & $28.44 \pm 2.331^{\mathrm{a}}$ \\
100 & $26.03 \pm 1.897$ & $35.51 \pm 0.383^{\mathrm{a}}$ \\
200 & $32.40 \pm 1.296$ & $41.87 \pm 0.949^{\mathrm{a}}$
\end{tabular}

${ }^{\mathrm{a}} \mathrm{P}<0.05$, lenalidomide vs. thalidomide.

Table II. Expression of activated caspase-3 in each drug concentration group.

\begin{tabular}{lcc}
\hline Drug & $100 \mu \mathrm{g} / \mathrm{ml}$ & $200 \mu \mathrm{g} / \mathrm{ml}$ \\
\hline Thalidomide & $13.37 \pm 1.95$ & $20.75 \pm 1.75$ \\
Lenalidomide & $16.90 \pm 1.54^{\mathrm{a}}$ & $24.31 \pm 2.24^{\mathrm{a}}$
\end{tabular}

${ }^{\text {aP }}<0.05$, lenalidomide vs. thalidomide.

Table III. Expression of vascular endothelial growth factor in each drug concentration group.

\begin{tabular}{lcc}
\hline Drug & $100 \mu \mathrm{g} / \mathrm{ml}$ & $200 \mu \mathrm{g} / \mathrm{ml}$ \\
\hline Thalidomide & $0.4985 \pm 0.01097$ & $0.2460 \pm 0.01192$ \\
Lenalidomide & $0.3760 \pm 0.01813^{\mathrm{a}}$ & $0.2255 \pm 0.01921$ \\
\hline
\end{tabular}

${ }^{\mathrm{a}} \mathrm{P}<0.05$, lenalidomide vs. thalidomide.

Lenalidomide promotes apoptosis in SMMC-7721 cells. Cells $\left(5 \times 10^{5}\right)$ were treated with lenalidomide and thalidomide at the indicated doses for $48 \mathrm{~h}$. Typical apoptotic morphological alterations were observed using fluorescence microscopy, and included cell nucleus shrinkage, chromatin condensation and the appearance of apoptotic bodies when treated with different doses of the drugs tested (Fig. 2). Lenalidomide was observed to exhibit an increased effect of inducing cell apoptosis than thalidomide at the same concentration (Fig. 2). Caspase-3 activity of samples was detected using a microplate reader, and the OD was analyzed at $405 \mathrm{~nm}$. Activity of caspase-3 was upregulated with increased lenalidomide and thalidomide concentrations. Caspase-3 activity in the lenalidomide groups was greater than in the thalidomide groups at the same concentrations, and this difference was significant $(16.69 \pm 1.54$ vs. $13.37 \pm 1.59 ; 24.31 \pm 2.24$ vs. $20.75 \pm 1.75 ; \mathrm{P}<0.01, \mathrm{P}<0.05$; Fig. $1 \mathrm{~B}$, Table II). Hepatoma SMMC-7721 cell apoptosis was examined using the Annexin-V staining-based FACS assay following lenalidomide and thalidomide treatment for $48 \mathrm{~h}$. The rate of apoptosis is presented in Fig. 3. Lenalidomide has a higher rate
A

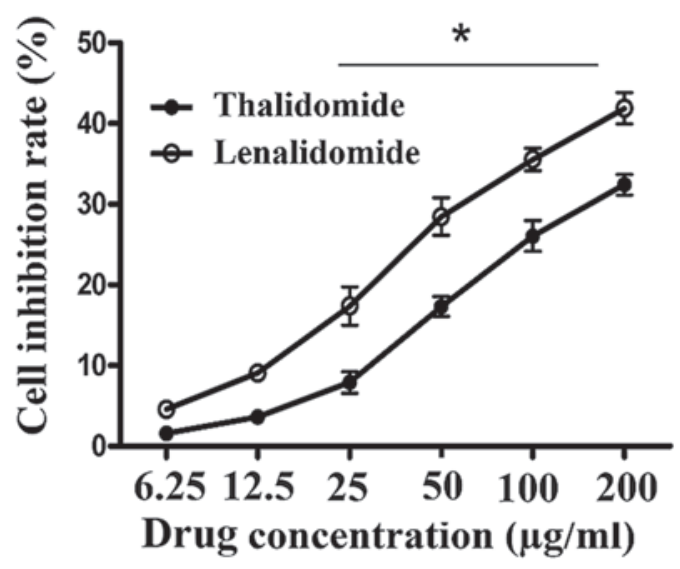

B

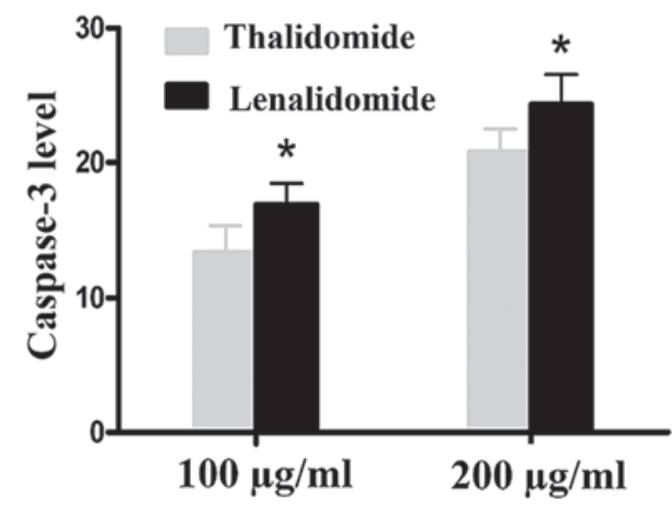

C

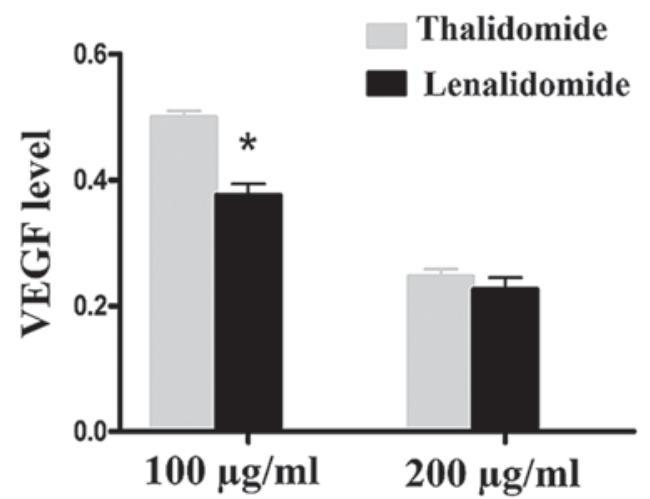

Figure 1. (A) Lenalidomide and thalidomide can significantly inhibit proliferation of SMMC-7721 cells. (B) Caspase-3 activation was indirectly determined by the rate of induced group OD and control group OD. The OD rate in the lenalidomide group was significantly higher than in the thalidomide groups with the same concentration. (C) Lenalidomide significantly inhibits VEGF expression of SMMC-7721 cells in vitro and is significantly more efficacious than thalidomide in the $100 \mu \mathrm{g} / \mathrm{ml}$ group. No significant differences were observed between the $200 \mu \mathrm{g} / \mathrm{ml}$ groups. ${ }^{*} \mathrm{P}<0.05$. OD, optical density; VEGF, vascular endothelial growth factor.

of induced cell apoptosis than thalidomide of the same concentration ( $\mathrm{P}<0.01$; Fig. 3 ), and the effect was observed to be greater with the increase of the lenalidomide concentration (Fig. 4).

Lenalidomide inhibits VEGF expression in SMMC-7721 cells. The data were presented as the mean \pm standard deviation. 

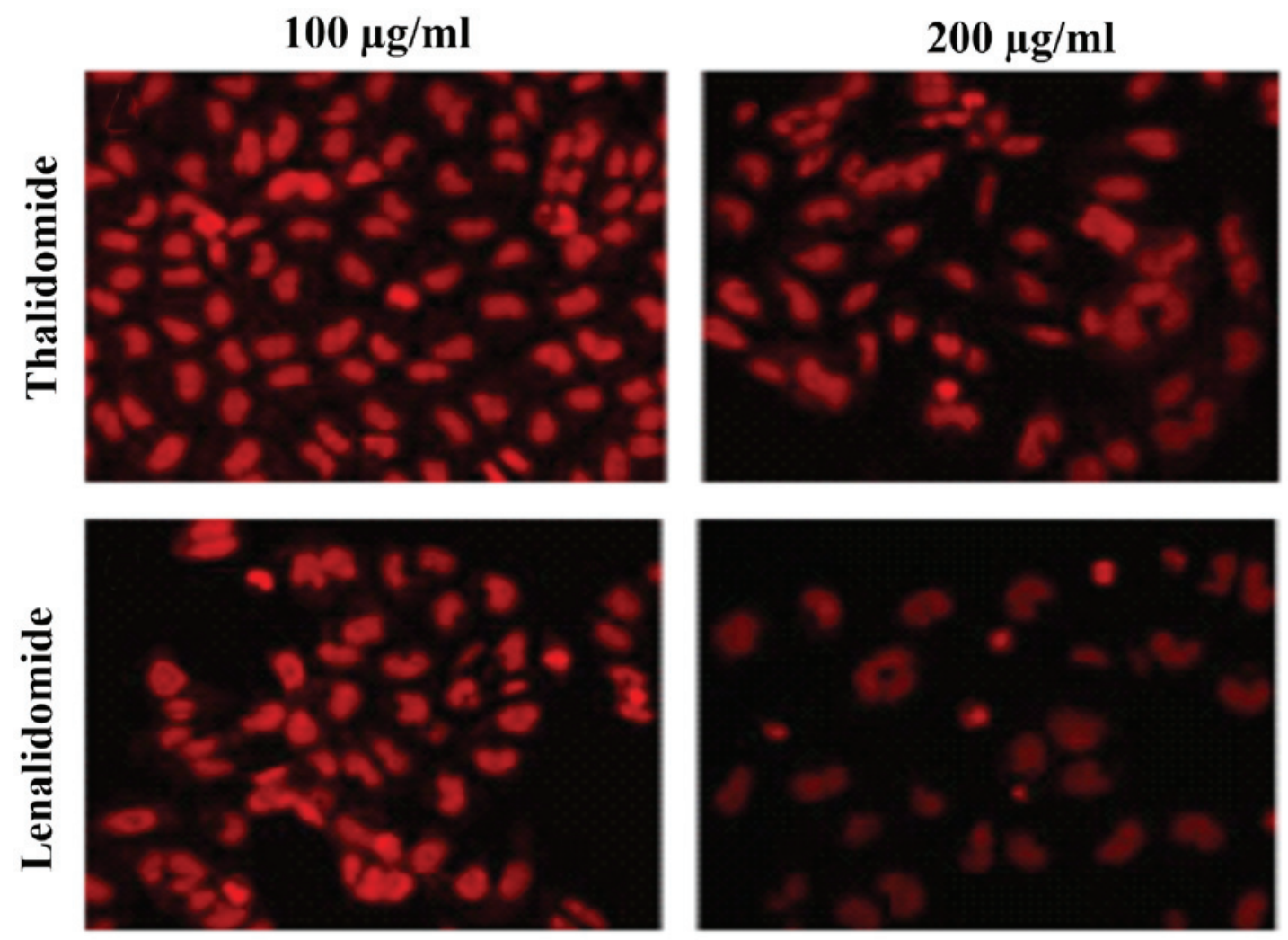

Figure 2. The typical apoptotic morphological alterations were observed by fluorescence microscopy. These included shrinkage of the cell nucleus, chromatin condensation and the appearance of apoptotic bodies with drug treatment.
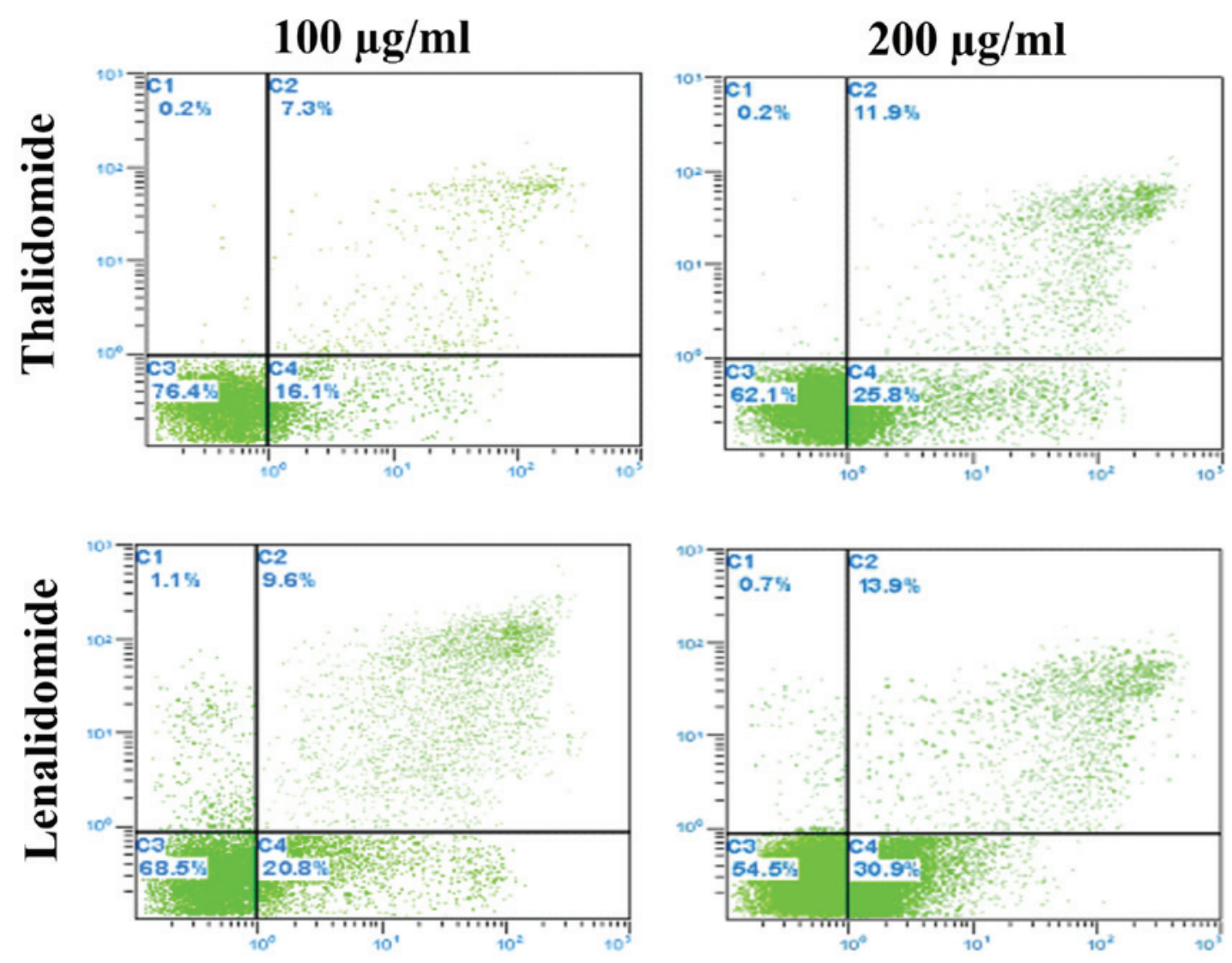

Figure 3. Cells $\left(5 \times 10^{5}\right)$ were treated with 100 or $200 \mu \mathrm{g} / \mathrm{ml}$ drugs (lenalidomide and thalidomide) for $48 \mathrm{~h}$ then were detected by Annexin V-fluorescein isothiocyanate/propidium iodide. Lenalidomide was observed to have a higher rate of induced cell apoptosis than thalidomide at the same concentration $(\mathrm{P}<0.01)$. 
A

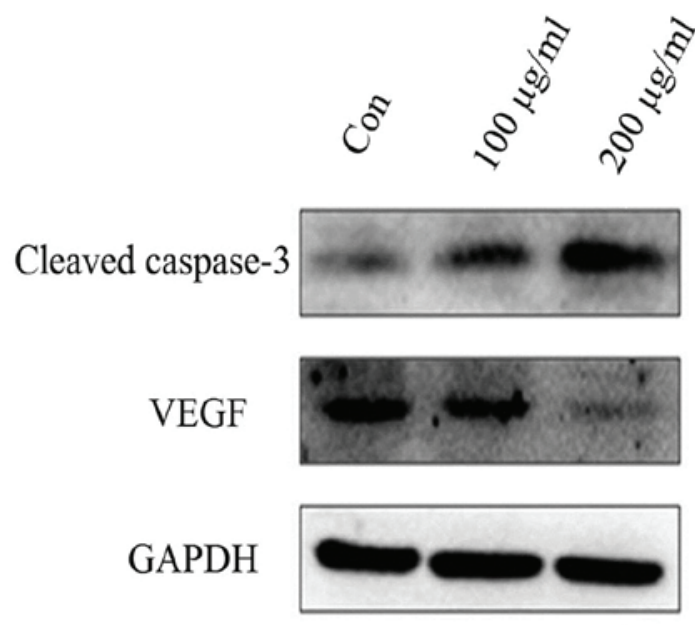

B

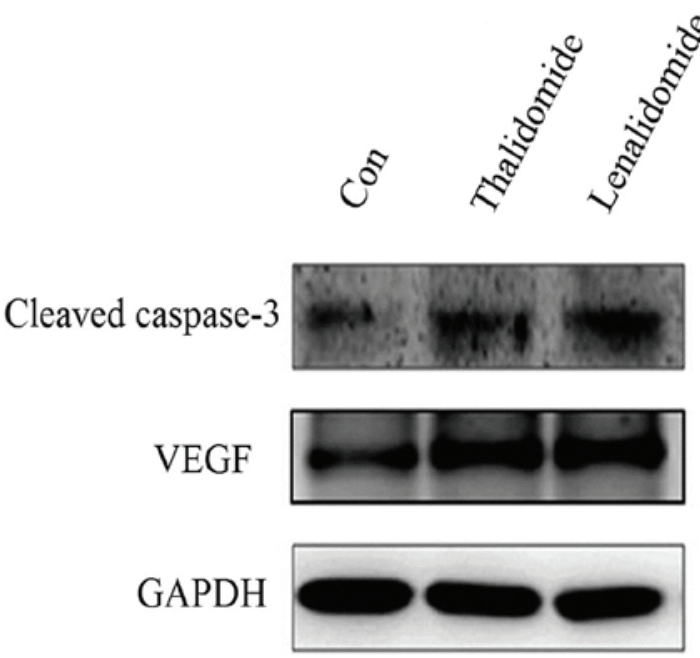

Figure 4. Expression of cleaved caspase-3 and VEGF in SMMC-7721 cells treated with or without lenalidomide; GAPDH was set as internal standard to normalize loadings. (A) Lenalidomide can significantly promote cleaved caspase-3 expression and inhibit VEGF expression of SMMC-7721 cells in vitro. (B) Lenalidomide is more potent than thalidomide in $100 \mathrm{ug} / \mathrm{m}$ groups and it has not significant difference between $200 \mathrm{ug} / \mathrm{m}$ groups. VEGF, vascular endothelial growth factor; Con, control.

In the current study, it was observed that lenalidomide can significantly inhibit VEGF expression of SMMC-7721 cells in vitro (Fig. 4) and is more potent than thalidomide in the $100 \mu \mathrm{g} / \mathrm{ml}$ groups $(0.3760 \pm 0.01813 ; 0.4985 \pm 0.01097 ; \mathrm{P}<0.05)$. No significant differences were observed between the $200 \mu \mathrm{g} / \mathrm{ml}$ groups $(0.2255 \pm 0.01921 ; 0.2460 \pm 0.01192 ; \mathrm{P}>0.05$; Fig. 1C, Table III).

\section{Discussion}

Lenalidomide is a novel analogue of thalidomide and previous studies have demonstrated its anticancer effects $(8,9,14)$. The results of the current study demonstrated that lenalidomide and thalidomide can significantly inhibit the proliferation of the human SMMC-7721 HCC cell line. These suggested that lenalidomide has anti-proliferative activity for HCC cell lines in vitro, and the same effect of lenalidomide inhibiting cell proliferation has been observed in multiple myeloma cell lines (15). In addition, in the present study typical apoptotic morphological alterations were identified by fluorescence microscopy, including cell nucleus shrinkage, chromatin condensation and the presence of apoptotic bodies with treatment with different doses of the drugs.

Caspase- 3 is an intracellular protease activated early during apoptosis of cells and serves an important role in cell apoptosis. This protease activity can be measured spectrophotometrically by detection of the chromophore ( $p$-nitroanilide) subsequent to cleavage from the labeled substrate (DEVD-pNA). In previous studies, Dmoszynska et al (11) reported that the mixture of lovastatin and thalidomidemay increases the rate of multiple myeloma cell apoptosis. Ezell et al (16) observed that low dose thalidomide treatment of human $\mathrm{T}$ leukemic cells exhibited rapid increases in caspase- 3 activity, in addition, thalidomide and its immunomodulatory analogs trigger activation of caspase-8, enhancing MM cell sensitivity to Fas-induced apoptosis (17). The current study identified that activity of caspase-3 is upregulated with increases in lenalidomide and thalidomide concentration, and caspase-3 activity in lenalidomide groups is significantly higher than that of the thalidomide groups with the same concentrations $(\mathrm{P}<0.05$; Figs. 1B and 4 and Table II). The present study indicated that lenalidomide inhibits proliferation of SMMC-7721 cells via the induction of cell apoptosis and suggested that caspase- 3 may serve an important role in this process.

Angiogenesis serves an important role during tumor growth, invasion and metastasis (18), and VEGF is an endothelial-specific growth factor that stimulates endothelial function and angiogenesis (15). A previous study identified that lenalidomide possesses anti-angiogenic activity, and enhances T cell proliferation in MM patients (8). Tan et al (7) demonstrated that thalidomide can suppress VEGF and hypoxia-inducible factor $1 \alpha$ in a dose-dependent manner $(\mathrm{P}<0.05)$. In the present study, it was demonstrated that lenalidomide can significantly inhibit VEGF expression of SMMC-7721 cells in vitro, and is more potent than that of thalidomide in the $100 \mu \mathrm{g} / \mathrm{ml}$ groups $(\mathrm{P}<0.05$; Figs. $1 \mathrm{C}$ and 4 and Table III). No significant difference was observed between the $200 \mu \mathrm{g} / \mathrm{ml}$ groups $(\mathrm{P}>0.05)$, These results indicated that the anti-angiogenesis activity of lenalidomide was induced through suppression of VEGF, and this may be a critical factor in the inhibition of cell proliferation.

Taken together, the results suggest that the inhibition of SMMC-7721 cell proliferation by lenalidomide in vitro is more potent than that of thalidomide and in addition, induction of apoptosis and inhibition of angiogenesis may be two potential mechanisms for its anti-HCC activity.

\section{Acknowledgements}

The present study was supported by the Science and Technology Projects (grant no. CY20119002) from the Changzhou Science and Technology Bureau of China. The authors would 
like to thank Dr Peng Jiang for the technical assistance and Professor Yong Jiang for the helpful discussion.

\section{References}

1. El-Serag HB and Mason AC: Rising incidence of hepatocellular carcinoma in the United States. N Engl J Med 340: 745-750, 1999.

2. Sangiovanni A, Del Ninno E, Fasani P, De Fazio C, Ronchi G, Romeo R, Morabito A, De Franchis R and Colombo M: Increased survival of cirrhotic patients with a hepatocellular carcinoma detected during surveillance. Gastroenterology 126: 1005-1014, 2004.

3. Merchant N, David CS and Cunningham SC: Early hepatocellular carcinoma: Transplantation versus resection: The case for liver resection. Int J Hepatol 2011: 142085, 2011.

4. Burrel M, Reig M, Forner A, Barrufet M, de Lope CR, Tremosini S, Ayuso C, Llovet JM, Real MI and Bruix J: Survival of patients with hepatocellular carcinoma treated by transarterial chemoembolisation (TACE) using drug eluting beads. Implications for clinical practice and trial design. J Hepatol 56: 1330-1335, 2012.

5. Settles B, Stevenson A, Wilson K, Mack C, Ezell T, Davis MF and Taylor LD: Down-regulation of cell adhesion molecules LFA-1 and ICAM-1 after in vitro treatment with the anti-TNF-alpha agent thalidomide. Cell Mol Biol (Noisy-le-grand) 47: 1105-1114, 2001.

6. Sun P, Zhang LM, Sun DJ and Dong LL: Inhibitory effect of thalidomide on growth of human hepatoma cell line SMMC 7721 cells. Zhonghua Zhong Liu Za Zhi 31: 582-586, 2009 (In Chinese)

7. Tan H, Chen H, Xu C, Ge Z, Gao Y, Fang J, Liu W and Xiao S: Role of vascular endothelial growth factor in angiodysplasia: An interventional study with thalidomide. J Gastroenterol Hepatol 27: 1094-1101, 2012.

8. Galustian C, Meyer B, Labarthe MC, Dredge K, Klaschka D, Henry J, Todryk S, Chen R, Muller G, Stirling D, et al: The anti-cancer agents lenalidomide and pomalidomide inhibit the proliferation and function of T regulatory cells. Cancer Immunol Immunother 58: 1033-1045, 2009.
9. Agliano A, Martin-Padura I, Marighetti P, Gregato G, Calleri A, Prior C, Redrado M, Calvo A and Bertolini F: Therapeutic effect of lenalidomide in a novel xenograft mouse model of human blastic NK cell lymphoma/blastic plasmacytoid dendritic cell neoplasm. Clin Cancer Res 17: 6163-6173, 2011.

10. Park E, Levis WR, Greig N, Jung E and Schuller-Levis G: Effect of thalidomide on nitric oxide production in lipopolysaccharide-activated RAW 264.7 cells. J Drugs Dermatol 9: 330-333, 2010

11. Dmoszynska A, Podhorecka M, Klimek P and Grzasko N: Lovastatin and thalidomide have a combined effect on the rate of multiple myeloma cell apoptosis in short term cell cultures. Eur J Clin Pharmacol 62: 325-329, 2006.

12. Dmoszynska A, Podhorecka M, Manko J, Bojarska-Junak A, Rolinski J and Skomra D: The influence of thalidomide therapy on cytokine secretion, immunophenotype, BCL-2 expression and microvessel density in patients with resistant or relapsed multiple myeloma. Neoplasma 52: 175-181, 2005.

13. Vaithilingam V, Oberholzer J, Guillemin GJ and Tuch BE: Beneficial effects of desferrioxamine on encapsulated human islets-in vitro and in vivo study. Am J Transplant 10: 1961-1969, 2010.

14. van de Donk NW, Wittebol S, Minnema MC and Lokhorst HM: Lenalidomide (Revlimid) combined with continuous oral cyclophosphamide (endoxan) and prednisone (REP) is effective in lenalidomide/dexamethasone-refractory myeloma. $\mathrm{Br} \mathrm{J}$ Haematol 148: 335-337, 2010.

15. Rao KV: Lenalidomide in the treatment of multiple myeloma. Am J Health Syst Pharm 64: 1799-1807, 2007.

16. Ezell TN, Maloney N, Githua JW and Taylor LD: Exposure to the anti-TNF-alpha drug thalidomide induces apoptotic cell death in human T leukemic cells. Cell Mol Biol (Noisy-le-grand) 49: $1117-1124,2003$.

17. Mitsiades N, Mitsiades CS, Poulaki V, Chauhan D, Richardson PG, Hideshima T, Munshi NC, Treon SP and Anderson KC: Apoptotic signaling induced by immunomodulatory thalidomide analogs in human multiple myeloma cells: Therapeutic implications. Blood 99: 4525-4530, 2002.

18. Folkman J: Tumor angiogenesis: Therapeutic implications. N Engl J Med 285: 1182-1186, 1971. 